\title{
The Effects of Chromium and Titanium Gettering on the Operation of the Advanced Toroidal Facility*
}

\author{
R. C. Isler, G. L. Bell, T. S. Bigelow, E. C. Crume, A. C. England, \\ J. C. Glowienka, S. Hiroe, L. D. Horton, T. C. Jernigan, R. A. Langley, \\ P. K. Mioduszewski, M. Murakami, D. A. Rasmussen, J. E. Simpkins, \\ J. B. Wilgen, and W. R. Wing
}

\author{
Fusion Energy Division \\ Oak Ridge National Laboratory \\ Oak Ridge, TN 37831 \\ USA
}

\begin{abstract}
DISCLAIMER
This report was prepared as an account of work sponsored by an agency of the United States Government. Neither the United States Government nor any agency thereof, nor any of their employees, makes any warranty, express or implied, or assumes any legal liability or responsibility for the accuracy, completeness, or usefulness of any information, apparatus, product, or process disclosed, or represents that its use would not infringe privately owned rights. Reference herein to any specific commercial product, process, or service by trade name, trademark, manufacturer, or otherwise does not necessarily constitute or imply its endorsement, recommendation, or favoring by the United States Government or any agency thereof. The views and opinions of authors expressed herein do not necessarily state or reflect those of the United States Government or any agency thereof.
\end{abstract}

* Work sponsored by the Office of Fusion Energy, U. S. Department of Energy, under contract No. DE-ÄC05-84OR21400 with Martin Marietta Energy Systems Inc. 


\section{Abstract}

Plasmas in the Advanced Toroidal Facility (ATF), an $\ell=2$ torsatron with 12 field periods, are produced by $200-400 \mathrm{~kW}$ of electron cyclotron heating (ECH) and up to $1.5 \mathrm{MW}$ of neutral-beam injection (NBI). The characteristics of the plasmas are sensitive to the type of wall conditioning employed. A progression of techniques, beginning with glow discharge cleaning and baking and evolving to gettering with chromium and titanium, has significantly reduced the low-Z impurity content, lowered the fraction of radiated power, and permitted improved control over the electron density. As a result, plasma parameters and machine performance have been enhanced significantly. The maximum values achieved for stored energy, line-averaged density, and confinement times are $28 \mathrm{~kJ}, 1.2 \times 10^{20} \mathrm{~m}^{-3}$, and $25 \mathrm{~ms}$. These parameters are comparable to those obtained in the ISX-B tokamak. In addition, with titanium gettering, quasisteady operation for $200 \mathrm{~ms}$ of neutral beam injection has been obtained without the collapses that characterized earlier periods of operation. 


\section{Introduction}

The Advanced Toroidal Facility (ATF) is an $\ell=2$ torsatron having 12 field periods. In the standard configuration the rotational transform, $t$, varies from 0.3 on the magnetic axis to 1.0 at the edge [1]. Plasma heating capabilities include $400 \mathrm{~kW}$ of $53 \mathrm{GHz} \mathrm{ECH}$ power and 1.5 MW of tangentially injected NBI power; Ohmic currents are not employed for heating. During the past year, substantial improvements in the maximum values of several plasma parameters The stored energy has increased from 8 to $27 \mathrm{~kJ}$, the line averaged density from $3.5 \times 10^{19} \mathrm{~m}^{-3}$ to $1.2 \times 10^{20} \mathrm{~m}^{-3}$, and the average $\beta$ from $0.7 \%$ to $1.5 \%$. Confinement times as long as $25 \mathrm{~ms}$ have been achieved with $1.2 \mathrm{MW}$ of NBl. These times are as long as the best confinement times observed in the ISX-B tokamak which had approximately the same minor radius and about one-half the major radius of ATF. The improvement of these parameters has resulted partially from implementing operation at $1.9 \mathrm{~T}$, i.e., at twice the field used for previous operations, and partially from improved wall conditioning via chromium and titanium gettering. Although gettering was introduced primarily to minimize the low-Z impurity content, which was thought to be a contributing factor to the collapses sometimes observed in $\mathrm{E}: \mathrm{JH}$ plasmas and always in NBI plasmas [2], it also proved most useful for suppressir.g hydrogen released or recycled from the walls, thereby allowing the electron density to be controlled almost entirely through gas puffing. In this paper we discuss the changes in various characteristics of ATF which have been brought about by gettering: partial pressures of the residual gas, impurity content and impurity radiation during discharges, control of the electron density, and operating scenarios leading to high stored energies.

\section{Base pressure characteristics}

The composition of the background gas in ATF was monitored regularly to evaluate the effectiveness of the wall conditioning procedures and to see if any correlation existed 
between the residual gas analyzer (RGA) measurements and the spectroscopic evaluations of low-Z impurity radation. Partial pressures of of mass 16 and mass 18 , primarily methane and water, observed after various types of wall conditioning are shown in Fig. 1. The first two sets of measurements were made after one day and fifteen days respectively of baking and glow discharge cleaning following a vacuum opening. Significant reductions of carbon and oxygen in the residual gas were observed in this period before gettering was implemented. The mass 18 content was reduced by a factor of 8 and the mass 16 content by a factor of 5 . Subsequent gettering reduced the mass 18 content slowly but steadily until improvement of another factor of 2 was obtained by the time wall conditioning progressed to using titanium with $70 \%$ coverage. The mass 16 pressure did not consistently decrease with gettering, and in fact, it was greater throughout much of the gettering operation than it was during the best periods when using only glow discharge cleaning and baking. Altogether, the RGA data alone would not have indicated that the low- $\mathrm{Z}$ content of the plasmas was greatly affected by gettering. However, it will be shown in Sec. 3 that radiation from carbon and oxygen, particularly after titanium gettering, was reduced well below the level observed in nongettered discharges.

\section{Spectroscopic Studies of Impurity radiation}

Several detailed spectroscopic studies of impurity radiacion were performed throughout the various stages of wall conditioning in ATF. The primary purposes were to examine the effect of gettering on the concentrations and emissions of the individual major impurities, to determine whether the total radiative losses were reduced by changing the wall characteristics, and to investigate whether radiation could be responsible for the collapses. Emission rates for typical intense lines of dominant impurities are shown in Table I together with spectroscopic estimates of radiated power from several ECH discharges. The estimates of power losses are determined by adjusting the free parameters in an impurity transport code, STRAHL [3], until the calculated and measured emission rates agree for 
3 or 4 lines each of 2 or 3 impurities. The radiation is assumed to be constant on a flux surface. Trarsport coefficients consistent with those measured directly from laser ablation experiments are used in the simulation. Assessing the effects of gettering is somewhat complicated because sequences of discharges for which extensive data on impurity radiation exist were not all performed at the same electron density and because results vary from day to day even under the same operational conditions. But enough data were aquired to discern general trends. Also, it is helpful to realize that for low densities $\left(\bar{n}_{e} \leq 10^{19} \mathrm{~m}^{-3}\right)$, the oxygen radiation scales almost as $\bar{n}_{e}$, so that when this impurity dominates the emissive losses the radiated power can be approximately scaled.

Columns 1 and 2 of Table I show typical results from two nongettered sequences of discharges. The first of these was performed at a low density, $3.2 \times 10^{18} \mathrm{~m}^{-3}$, in order to avoid any collapse, but $50-60 \%$ of the $200 \mathrm{~kW}$ ECH input power was still radiated. The second set of data was taken after extensive discharge cleaning when higher plasma densities could be obtained without incurring a collapse, and the radiated power was $75 \%$ of the input power.

The first use of chromium reduced the peripheral line intensities of the low- $Z$ elements by factors of 2.5 to 5 when compared to discharges documented immediately before gettering (columns 2 and 3 of Table I). This result may appear to indicate that the concentrations of carbon, nitrogen, and oxygen were also reduced considerably, but measurements of the cential densities of these impurities from charge exchange excitation (CXE) showed that although carbon decreased $30 \%$, the oxygen content actually increased by the same fraction. These results agree with RGA data to the extent that the initial chromium gettering seemed to have only a minor irfluence on the carbon and oxygen content of the plasmas. The disparity between the edge and interior emissions can undoubtedly be attributed to gettering induced changes in the edge electron profiles to which the peripheral radiation is quite sensitive [4]. After evaluating the influence of differing electron densities, we conclude 
from the spectral analysis that although the first use of chromium did not significantly reduce the total radiation from the discharges documented immediately beforehand, after several gettering cycles, the total radiation was reduced by a factor of 1.4 .

The influence of titanium gettering on the impurity composition was much more dramatic than was the effect of chromium. Cases are shown in Table I for the first use of titanium with 4 sources that provided $50 \%$ wall coverage and for a later case with 7 sources that gave $70 \%$ wall coverage. The emissions from peripheral carbon and oxygen were reduced by factors of as much as 30 to 50 compared to nongettered discharges, and the central densities were lowered by a factor of 3 . The reduction of power losses from low- $\mathrm{Z}$ impurities that radiate strongly in the edge leads to higher edge temperatures and increased sputtering rates. As a result, the metal radiation becomes more important in gettered plasmas and actually dominates the radiated power when titanium is employed. Total radiation was reduced by factors of 2.5 to 3.5 , but because of the interchange of low$\mathrm{Z}$ and metallic ions, a lower limit of about $15-20 \%$ appears to be the minimum radiated power achievable in ATF. These conclusions concerning the strong influence of titanium on the plasma impurity composition and radiated power are not evident in the RGA data, which shows only a modest reduction in the residual water content and no decrease of methane when using only $50 \%$ coverage. From the present set of data, it is concluded that the partial pressures of the residual gases provide some indications of general trends in the cleanup but do not have a one-to-one correspondence with the impurity changes detected in the plasmas.

It must be noted that data from a wide angle bolometer support the spectroscopic analysis for total radiated power only for the titanium gettered cases where the low- $Z$ radiation is negligible. In the nongettered and chromium gettered experiments the spectral estimates are as much as a factor of 2.5 greater than those from the bolometer. In fact, the bolometer data indicate that the total radiated power is independent of the method of wall conditioning if a linear scaling with $\bar{n}_{e}$ is assumed. Although analyses to obtain 
total radiated power from spectroscopic data are rather complicated when compared to a simple bolometric measurement, such difficulties do not appear to be the source of the discrepencies, and it is believed that the spectroscopic analysis provides a more reliable picture of the trends in radiated power related to wall conditioning.

\section{Plasma Performance}

It is clear that gettering has led to improved plasma performance not only by lowering the level of radiated power but also by reducing the uncontrolled influx of gases evolved from the walls during a discharge. As a result, it has been possible to tailor the gas fueling and to control density increases during NBI so that relatively high stored energies $(28 \mathrm{~kJ})$ and long confinement times $(25 \mathrm{~ms})$ are realized. Such results were originally achieved in a transient state, but subsequent refinement of the programming of the gas fueling has allowed high density, high confinement discharges to be attained in a quasisteady state with little indication that they were evolving toward collapses.

The sequences in which transient maxima are achieved in the stored energy are of interest because they also manifest variations of particle confinement, possibly indicating that electric fields may play a strong role in these discharges. Figures 2-4 illustrate diagnostic signals from a set of titanium gettered plasmas in which stored energies of $22 \mathrm{~kJ}$ are achieved with 1.2 MW NBI in a magnetic field of $1.9 \mathrm{~T}$. The key to obtaining these conditions is a strong increase of the gas puff at the same time that the NBI is initiated. The intense gas pulse lasts for approximately $100 \mathrm{~ms}$ while the line averaged density increases from $7.5 \times 10^{18} \mathrm{~m}^{-3}$ to $6 \times 10^{19} \mathrm{~m}^{-3}$. The stored energy reaches an initial peak of $12 \mathrm{~kJ}$ at $160 \mathrm{~ms}$, but thereafter declines, and half of the energy is lost by $200 \mathrm{~ms}$. Thomson scattering measurements indicate that the electron temperature declines from $500 \mathrm{eV}$ to $300 \mathrm{eV}$ in this interval, although spectroscopic estimates indicate a drop of only $50 \mathrm{eV}$. Subsequently, a spontaneous reheating occurs and a second maximum in the stored energy occurs at $300 \mathrm{~ms}$ while Thomson scattering data show the central electron temperature 
rising to $350 \mathrm{eV}$. At $300 \mathrm{~ms}$ the plasmas do begin to collapse, but without gettering the reheating phenomenon is not observed, nor has it proved possible to raise the density so high without a quick collapse.

The impurity behavior during these discharges indicates that the particle transport is also changing in response to the gas puff. Radiation from the innermost ions such as O VIII (predominantly CXE) and Fe XVIII tends to track the stored energy, but emissions from ions located farther toward the edge of the plasmas tend to be out of phase with the stored energy. For example, the O VI radiation exhibits a peak around $205 \mathrm{~ms}$ when the stored energy has fallen to a temporary minimum, but then drops to a minimum around 300 ms when the stored energy has attained its maximum value of $23 \mathrm{~kJ}$. The total radiation (Fig. 4a) has a similar temporal behavior. The variations of temperature cannot be solely responsible for the observed impurity behavior. Rather, it appears that the impurity flux is outward during the period when the stored energy declines but inward when the stored energy is rising. This interpretation is borne out by the $\mathrm{H}_{\alpha}$ signal shown in Fig. $4 \mathrm{~b}$; it is also out of phase with the stored energy and has the time dependence expected if the particle and energy confinement track each other. The minimum in the total radiation at $300 \mathrm{~ms}$ appears to result from the changing impurity transport and seems to be only a minor factor in the occurence of a simultaneous peak in the stored energy signal. It is tempting to associate the observed behavior with changes of electric fields, which are known to have a decided influence on particle confinement in stellarators, but no direct or indirect (through rotation) measurements of such fields have yet been made in ATF.

\section{Summary}

The experience with gettering in ATF, particularly when titanium is employed, has proven to be very satisfactory. Total radiation levels have been reduced by factors as large as 2.5 from nongettered discharges and uncontrollable density rises owing to gases released from the walls have been eliminated. The consequent ability to generate NBI plasmas with 
delayed collapses or no collapses at all has lead to record stored energies, electron densities, and confinement times. It is anticipated that the addition of a third neutral beam in the near future will allow us to improve these parameters still further while increasing the electron and ion temperatures. 
Table I. Typical radiation in gigarayleighs from strong spectral lines of several impurities emitted from plasmas heated by $200 \mathrm{~kW}$ of ECH after various gettering procedures $\left(1 \mathrm{GR}=10^{15}\right.$ photons $\left./ \mathrm{cm}^{2}-\mathrm{s}\right)$. Units of $\bar{n}_{e}$ are $10^{18} / \mathrm{m}^{3}$, and $P_{\text {rad }}$ is expressed in $\mathrm{kW}$. Uncertainties in the spectroscopic estimates of total radiated power are estimated to be \pm $25 \%$.

\begin{tabular}{|c|c|c|c|c|c|c|c|}
\hline $\begin{array}{l}\text { Para- } \\
\text { meter }\end{array}$ & $\cdot$ & - & $\begin{array}{l}30 \% \\
\mathrm{Cr}\end{array}$ & $\begin{array}{l}30 \% \\
\mathrm{Cr}\end{array}$ & $\begin{array}{l}50 \% \\
\mathrm{Cr}\end{array}$ & $\begin{array}{l}50 \% \\
\mathrm{Ti}\end{array}$ & $\begin{array}{l}70 \% \\
\mathrm{Ti}\end{array}$ \\
\hline$\overline{\bar{n}_{e}}$ & 3.2 & 7.5 & 6.5 & 4.6 & 9.2 & 5.1 & 6.5 \\
\hline $\begin{array}{l}\text { O VI } \\
1032 \AA\end{array}$ & 12 & 50 & 20 & 25 & 42 & 2.2 & 1.3 \\
\hline $\begin{array}{l}\text { C III } \\
977 \AA\end{array}$ & 3.5 & 12 & 2.5 & 2.5 & 10 & 0.5 & 0.22 \\
\hline $\begin{array}{l}\text { N IV } \\
765 \AA\end{array}$ & 0.7 & 4.5 & 1.6 & 1.6 & 1.0 & 0.05 & 0.07 \\
\hline $\begin{array}{l}\mathrm{Fe} X \mathrm{XI} \\
360 \AA\end{array}$ & 1.8 & 0.5 & 1.5 & 0.8 & 3.2 & 1.3 & 1.2 \\
\hline $\begin{array}{l}\text { Cr XIII } \\
328 \AA\end{array}$ & 1.4 & 0.3 & 2.5 & 1.5 & 1.3 & 1.0 & 0.8 \\
\hline $\begin{array}{l}\text { Ti XII } \\
461 \AA\end{array}$ & - & - & - & - & - & 2.5 & 2.5 \\
\hline$P_{\text {rad }}^{O}$ & 33 & 93 & 70 & 37 & 71 & 4 & 3 \\
\hline$P_{\text {rad }}^{C}$ & 48 & 28 & 23 & 11 & 29 & 3 & 2 \\
\hline$P_{r a d}^{N}$ & 8 & 19 & 21 & 5 & 3 & 0 & 1 \\
\hline$P_{\text {rad }}^{F e}$ & 16 & 6 & 10 & 8 & 5 & 13 & 16 \\
\hline$P_{r a d}^{C r}$ & 5 & 2 & 20 & 8 & 7 & 7 & 5 \\
\hline$P_{r a d}^{T i}$ & 0 & 0 & 0 & 0 & 0 & 12 & 11 \\
\hline$P_{\text {:ad }}^{\text {spect }}$ & 115 & 148 & 144 & 69 & 116 & 45 & 39 \\
\hline
\end{tabular}




\section{References}

[1] J. F. Lyon et al., Fusion Technol. 10 (1986) 179.

[2] R. C. Isler, E. C. Crume, L. D. Horton, H. C. Howe, and G. S. Voronov, Nucl. Fusion 29 (1989) 1384.

[3] K. Berhinger,Description of the impurity transport code "'STRAHL', JET Report JET-R(87)08 (1987).

[4] R. C. Isler, E. C. Crume, and H. C. Howe, Nucl. Fusion 19 (1979) 727. 


\section{Figure Captions}

1. Residual gas analysis of mass 16 (methane) and mass 18 (water) signals for various gettering conditions.

2. Diagnostic signals from a sequence of discharges in which high stored energy is obtained transiently. $\bar{n}_{e} \approx n_{e} \ell / 0.65$

3. Spectral line emission rates from a high stored energy sequence. Signals are expressed in gigarayleighs ( $1 \mathrm{GR}=10^{15}$ photons $/ \mathrm{cm}^{2}-\mathrm{s}$. The $\mathrm{O}$ VIII line is produced dominantly by charge-exchange excitation.

4. Radiated power (bolometric) and $\mathrm{H}_{\mathrm{a}}$ signals from a high stored energy discharge. 
PARTIAL PRESSURE (TORR)

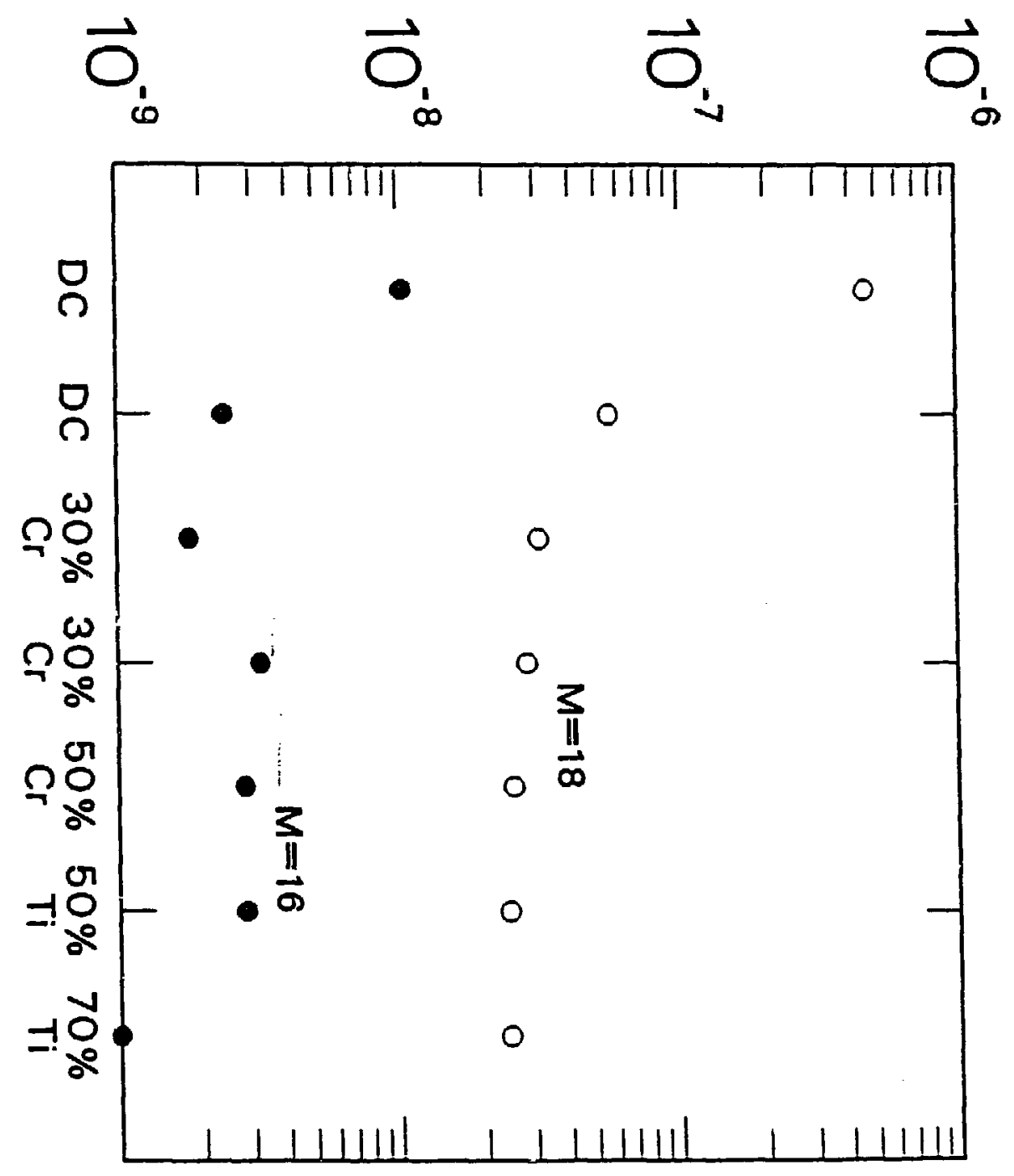




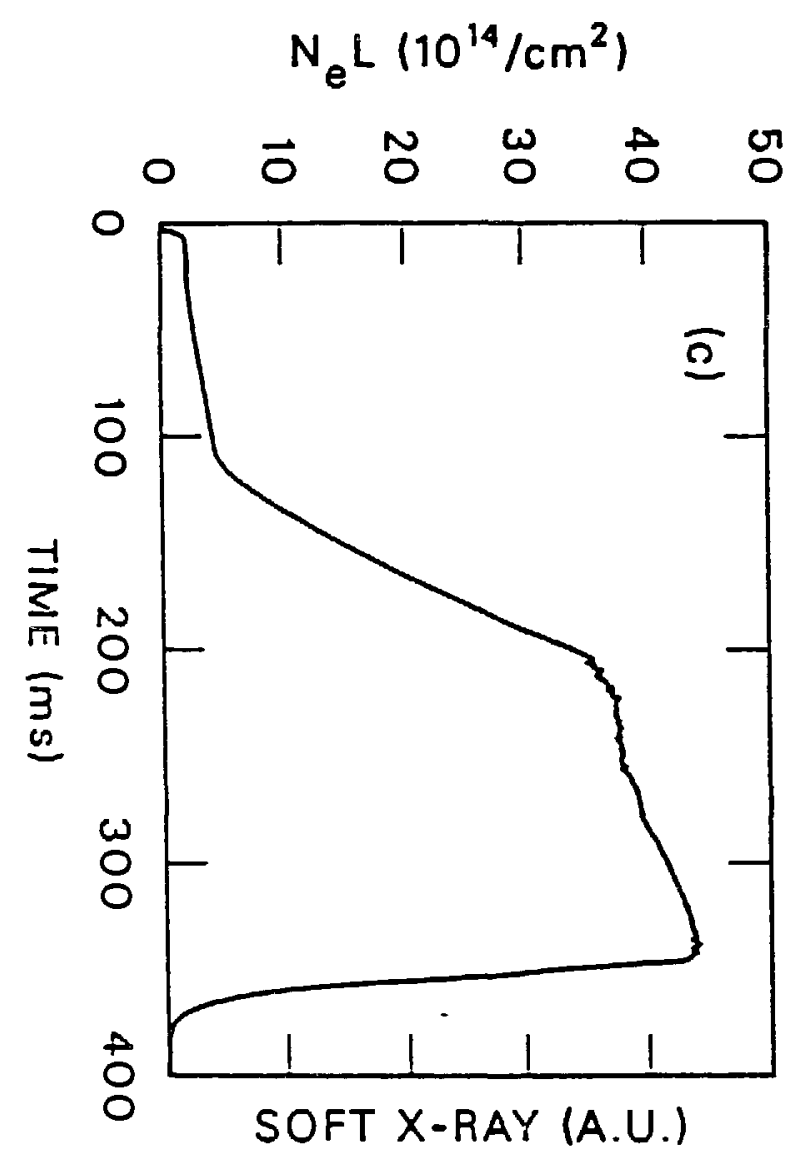

GAS PUFF (T-L/S)
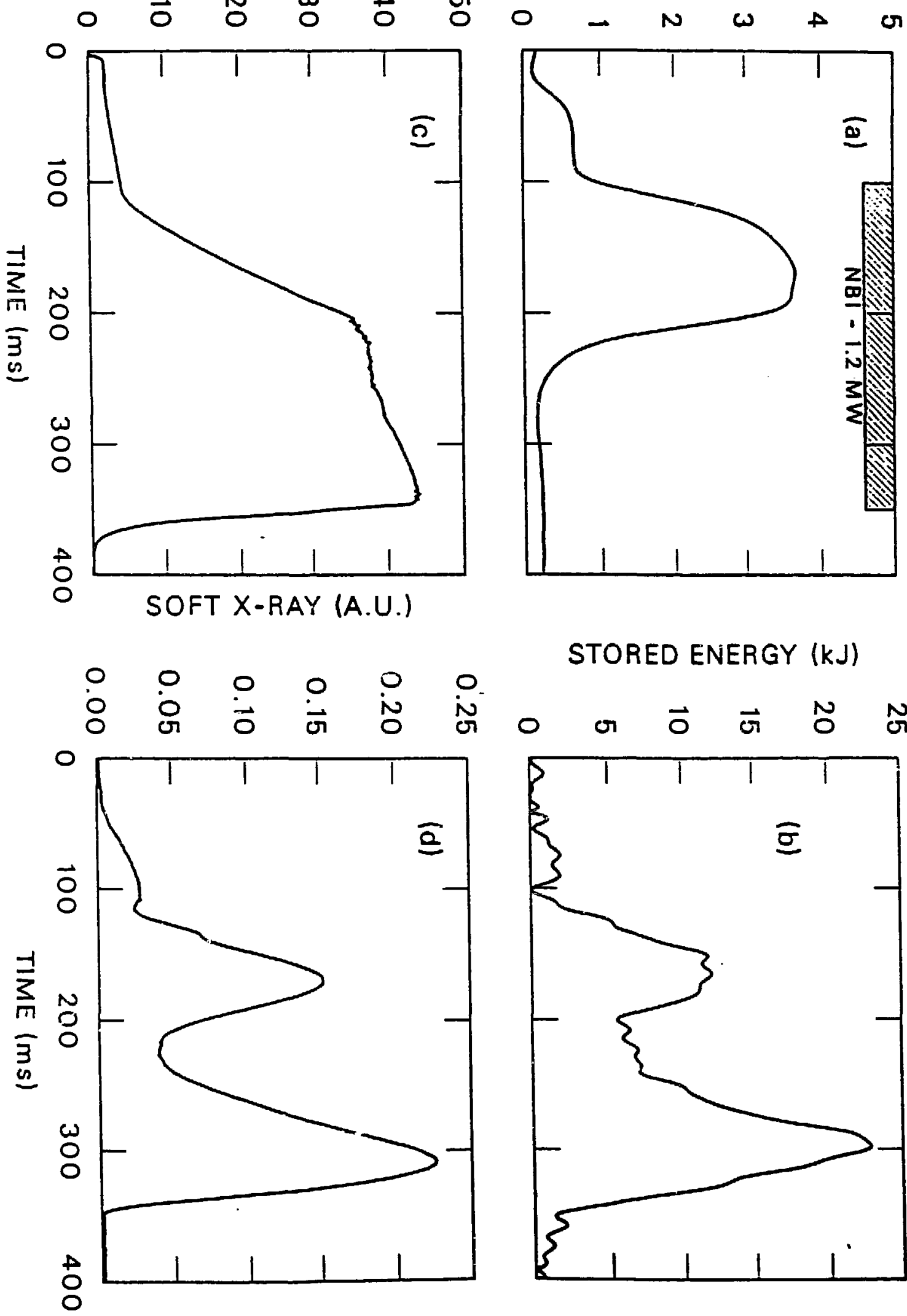

STORED ENERGY (kJ)

$\underset{\substack{N \\ 0}}{\vec{N}}$ 
EMISSION (GR)

\section{EMISSION (GR)}
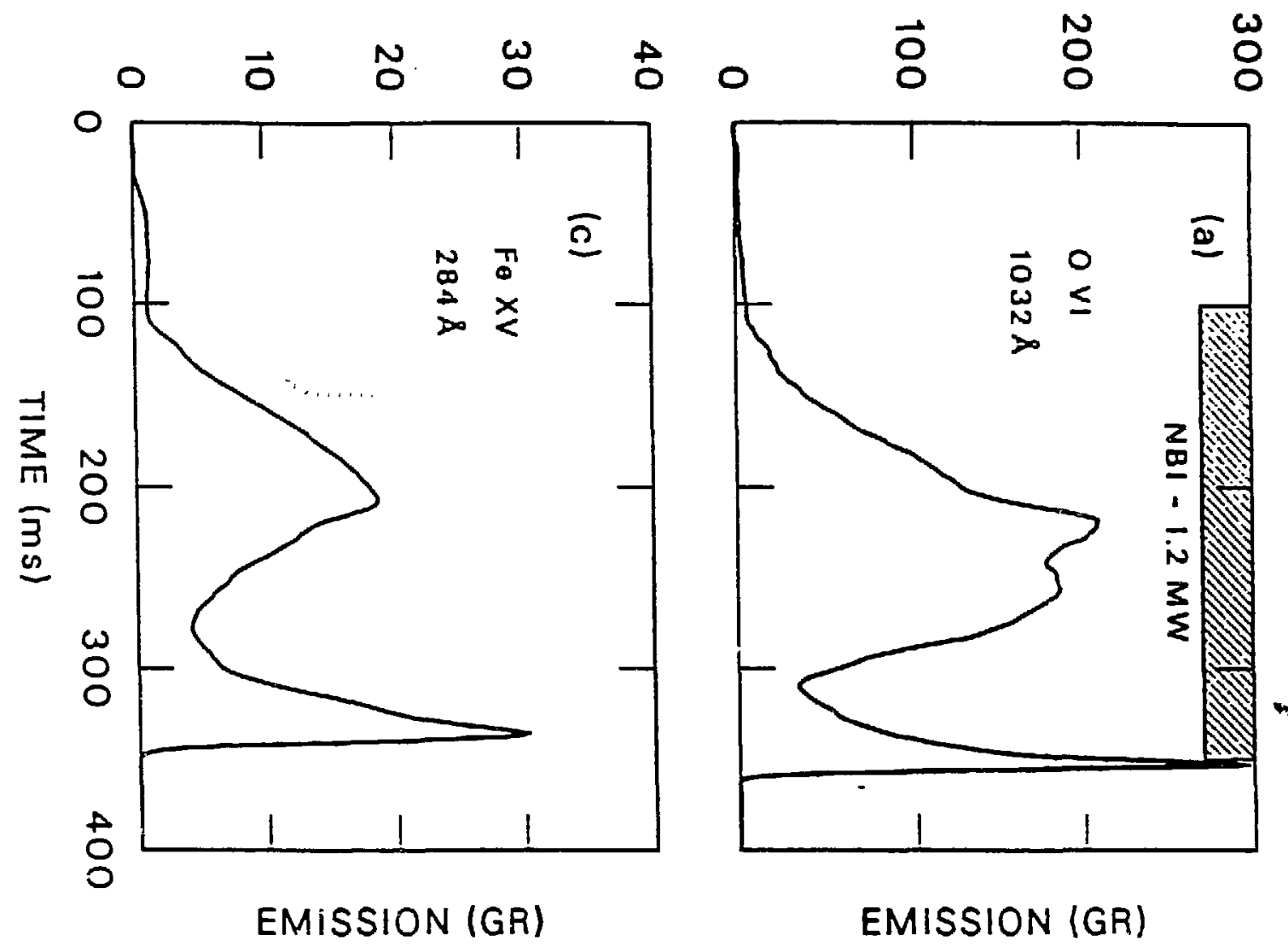

$\underset{⿱ 亠 N}{N}$

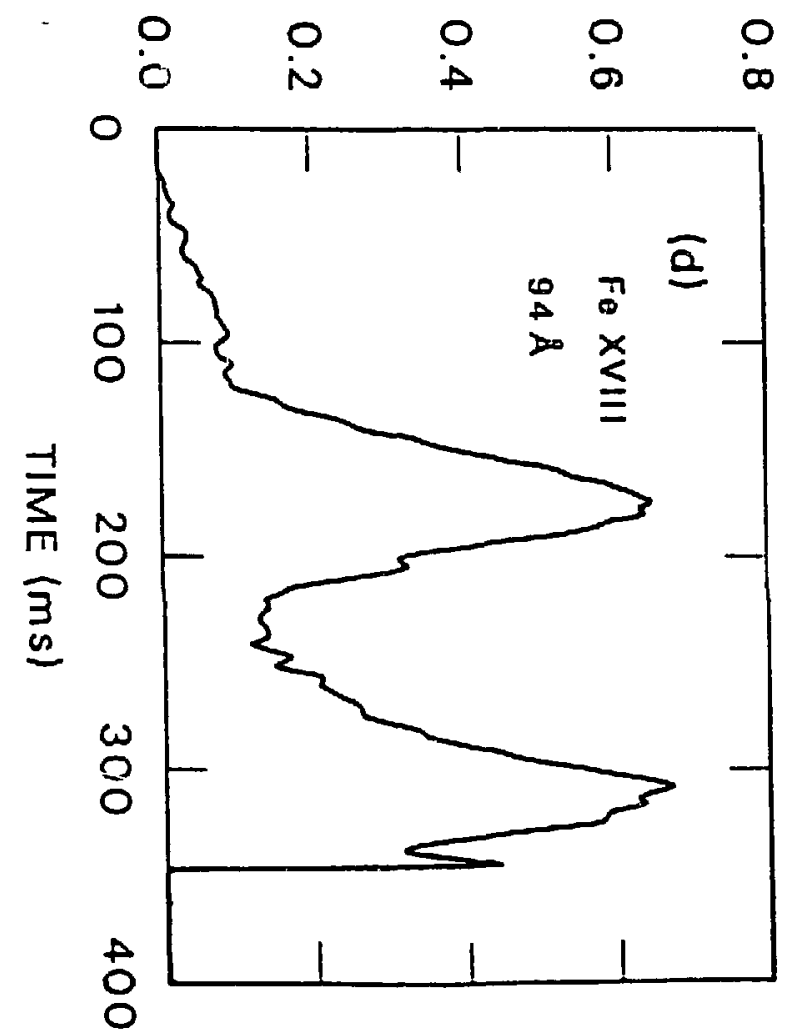

$\begin{array}{lllll}0 & 0 & 0 & 0 & 0 \\ 0 & i & i & 0 & \text { is }\end{array}$

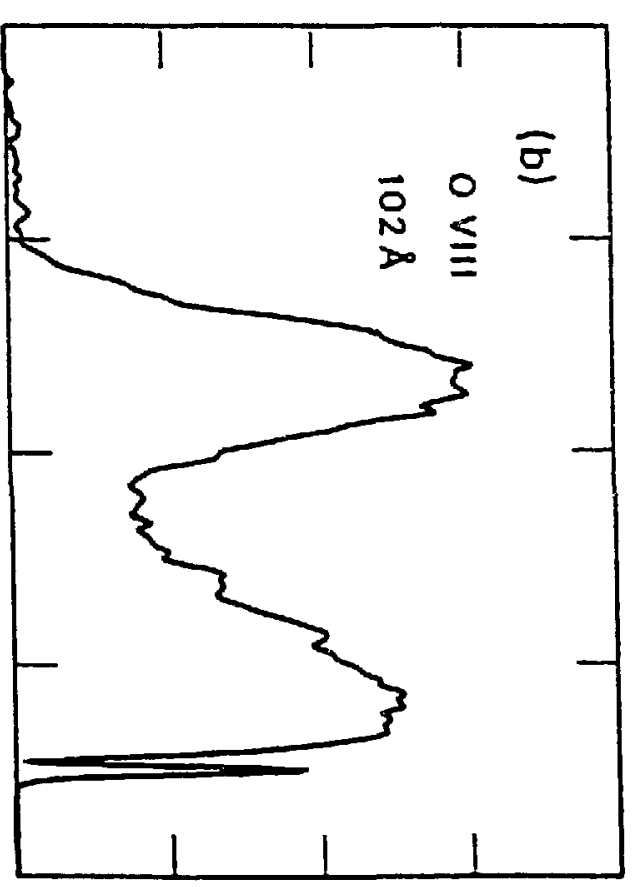



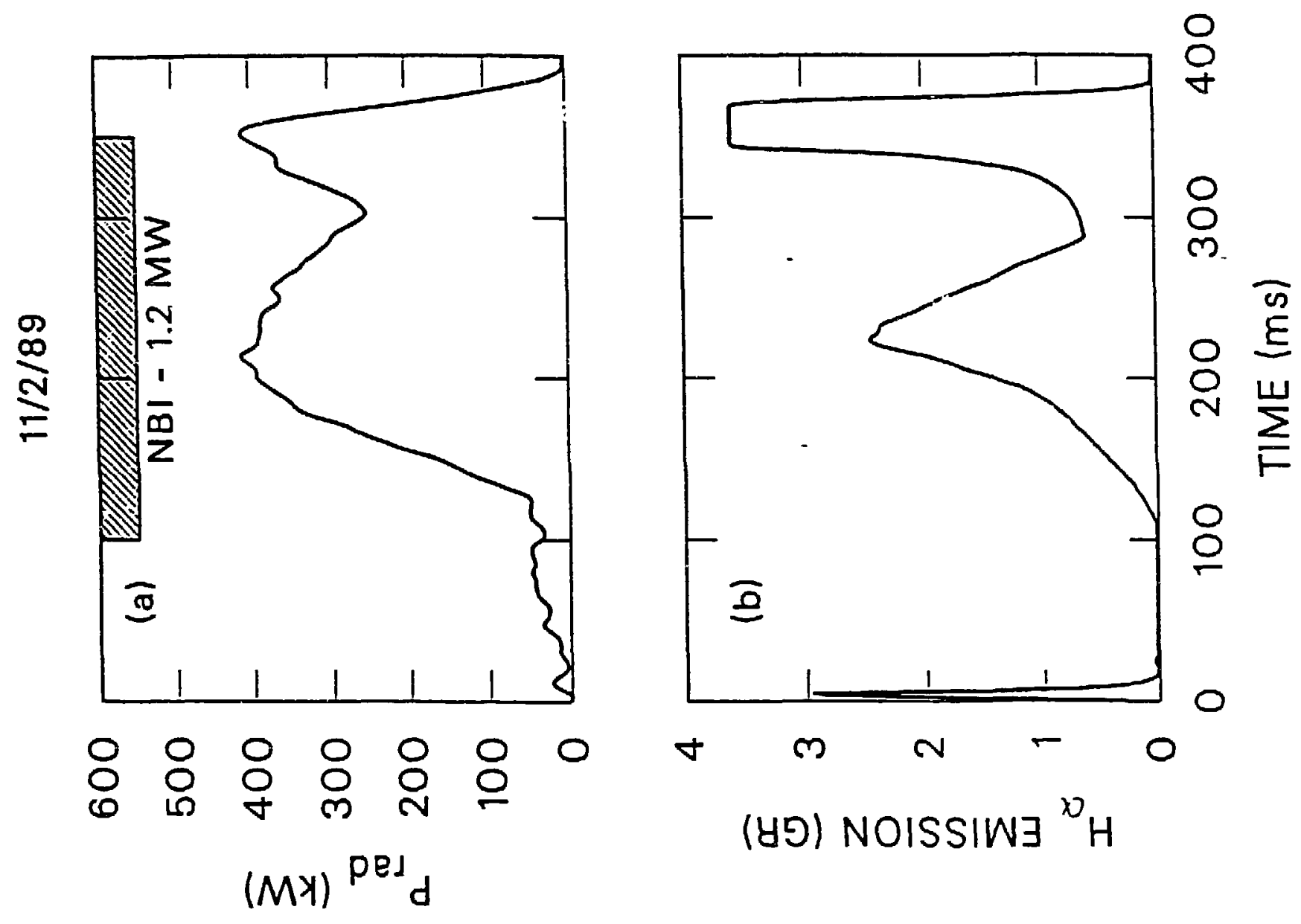